\title{
Surgical treatment of aneurysms of the ascending aorta associated with severe aortic regurgitation
}

\author{
MJ ANTUNES, AL BAPTISTA, PR COLSEN, RH KINSLEY \\ From the Department of Cardiothoracic Surgery, Johannesburg Group of Teaching Hospitals and the \\ University of the Witwatersrand, South Africa
}

\begin{abstract}
From January 1979 to June 198231 patients have had simultaneous ascending aortic aneurysm repair and aortic valve replacement. Fifteen patients (group 1) received a composite graft; seven patients (group 2) had separate aortic valve and supracoronary ascending aorta prostheses; and nine patients (group 3) had aortic valve replacement and "tailoring" of the ascending aorta. The mean age was 50 (SD 14) years. Nine patients had acute dissection, five with the coronary ostia affected. Emergency surgery was performed in 10 cases. There were six early deaths $(19.4 \%)$, none of them due to technical complications during surgery. The mortality rate was $56 \%$ for patients with acute dissection operated on as an emergency and $4.5 \%$ for patients having elective operations. Appreciable haemorrhage occurred in four patients (12.9\%). No neurological complications occurred. There was one late death. The survivors were followed up for one to four years. There was one case of recurrence of aneurysm. No ischaemic complications resulted from coronary reimplantation. There were no significant differences in the results of the three groups. Simultaneous ascending aortic aneurysm repair and aortic valve replacement can be accomplished with an acceptable mortality rate and little morbidity.
\end{abstract}

Successful surgical treatment of aneurysms of the ascending aorta associated with aortic regurgitation is a major challenge to the cardiovascular surgeon. The initial results of surgical treatment ${ }^{1}$ and of hypotensive drug treatment (Wheat regime ${ }^{2}$ ) were poor. Improvements in the techniques of cardiopulmonary bypass and recent advances in myocardial protection, however, as well as improved preoperative and postoperative management, have resulted in a dramatic decrease in the operative mortality for resection of dissecting and non-dissecting aneurysms, ${ }^{4-6}$ which is now much lower than that of medically treated patients. ${ }^{\text {? }}$

When appreciable aortic regurgitation is present, concomitant aortic valve replacement or repair and resection of the aneurysm are essential. ${ }^{89}$ Because of the diffuse characteristics of the disease, this type of surgery frequently does not cure. ${ }^{45}$ Consequently, in certain circumstances limited resection of the aortic wall ("tailoring") after aortic valve replacement or repair may be justified.

Address for reprint requests: Dr MJ Antunes, Department of Cardiothoracic Surgery, University of the Witwatersrand Medical School, York Road, Parktown, Johannesburg 2193, South Africa.

Accepted 28 November 1983
In this paper we report 31 cases of concomitant aortic valve replacement and ascending aortic aneurysm resection performed during three and a half years, from 1979 to 1982 .

\section{Patients and methods}

From January 1979 to June 198226 black and 5 white patients had aortic valve replacement with ascending aortic aneurysm repair. The mean age was 50 (SD 14) years (range 16-70); 24 were men and seven women. All but one patient had moderate to severe aortic valve regurgitation. Acute dissection occurred in nine patients, while the other 22 patients had fusiform or saccular aneurysms. Ten patients, including the nine with acute dissection, were operated on as an emergency. Acute left ventricular failure was the presenting feature in all but three of these. Five patients had significant angina and disease of the coronary ostia was confirmed at surgery in all. While acute dissection presented more urgently, there were no other differences in symptoms between these patients and those in the chronic group. All but three patients had radiological features of left ventricular and aortic root enlargement. The nature and extent of the lesions were confirmed 
Table 1 Results of surgery in 31 patients having ascending aortic aneurysm repair and aortic valve replacement

\begin{tabular}{|c|c|c|c|c|c|}
\hline & $\begin{array}{l}\text { No of } \\
\text { patients }\end{array}$ & $\begin{array}{l}\text { Complicating } \\
\text { features }\end{array}$ & $\begin{array}{l}\text { Type of } \\
\text { operation* }\end{array}$ & $\begin{array}{l}\text { No }(\%) \\
\text { of deaths }\end{array}$ & $\begin{array}{l}\text { Postoperative } \\
\text { complications }\end{array}$ \\
\hline $\begin{array}{l}\text { Acute dissection } \\
\text { Emergency operation }\end{array}$ & 99 & $\begin{array}{l}\text { Angina (5) } \\
\text { Renal failure (3) }\end{array}$ & $\begin{array}{l}1(3) \\
2(6)\end{array}$ & $5(55$ & Haemorrhage (1) \\
\hline $\begin{array}{l}\text { Chronic aneurysm } \\
\text { Emergency operation } \\
\text { Elective operation }\end{array}$ & $2^{1}{ }^{22}$ & Infective endocarditis & $\begin{array}{l}1(1) \\
1(11) \\
2(1) \\
3(9)\end{array}$ & $\begin{array}{l}0 \\
0 \\
0 \\
1\end{array}$ & $\begin{array}{l}\text { Haemorrhage (3) } \\
\text { Embolism (1) } \\
\text { Recurrence (1) }\end{array}$ \\
\hline Total & 31 & & & $6(1$ & \\
\hline
\end{tabular}

*1-composite graft; 2-separate aortic graft and supracoronary ascending aorta prostheses; 3-aortic valve replacement and "tailoring" of the ascending aorta.

by aortic arch angiography in most patients. In four patients, however, the aneurysm (three saccular, one fusiform) was unsuspected before operation and the indications for surgery were based on the aortic valve disease alone. More recently, the presence and characteristics of the aneurysms or acute dissection or both were confirmed by echocardiography. Dilatation of the aorta and an intimal flap were clearly seen in the proximal segment of the ascending aorta in the case of dissections. On three occasions the aneurysm was diagnosed only by echocardiography, the chest radiograph being within normal limits (fig). Contributing factors included hypertension in seven patients and atherosclerosis in two. Five patients had typical Marfan's syndrome and syphilis was diagnosed in four. In the remainder no aetiological factors could be established.
Standard techniques of cardiopulmonary bypass with moderate hypothermia $\left(22-28^{\circ} \mathrm{C}\right)$ were used in all patients. In most cases a single venous drainage cannula was placed in the right atrium, but more recently double cannulation of the vena cava has been preferred. Arterial cannulation of the ascending aorta was chosen when there was sufficient normal aorta between the aneurysm and the innominate artery. In the other cases and in acute dissections the right femoral artery was cannulated. Myocardial protection was achieved in all patients by direct intermittent perfusion of both coronary arteries with cold asanguineous cardioplegic solution (potassium $24 \mathrm{mmol}(\mathrm{mEq}) / \mathrm{l})$. Additionally, topical cooling with ice slush in the pericardial sac was used. In all patients the aortic valve (alone or in a conduit) was implanted with interrupted figure of $82 / 0$ Tycron

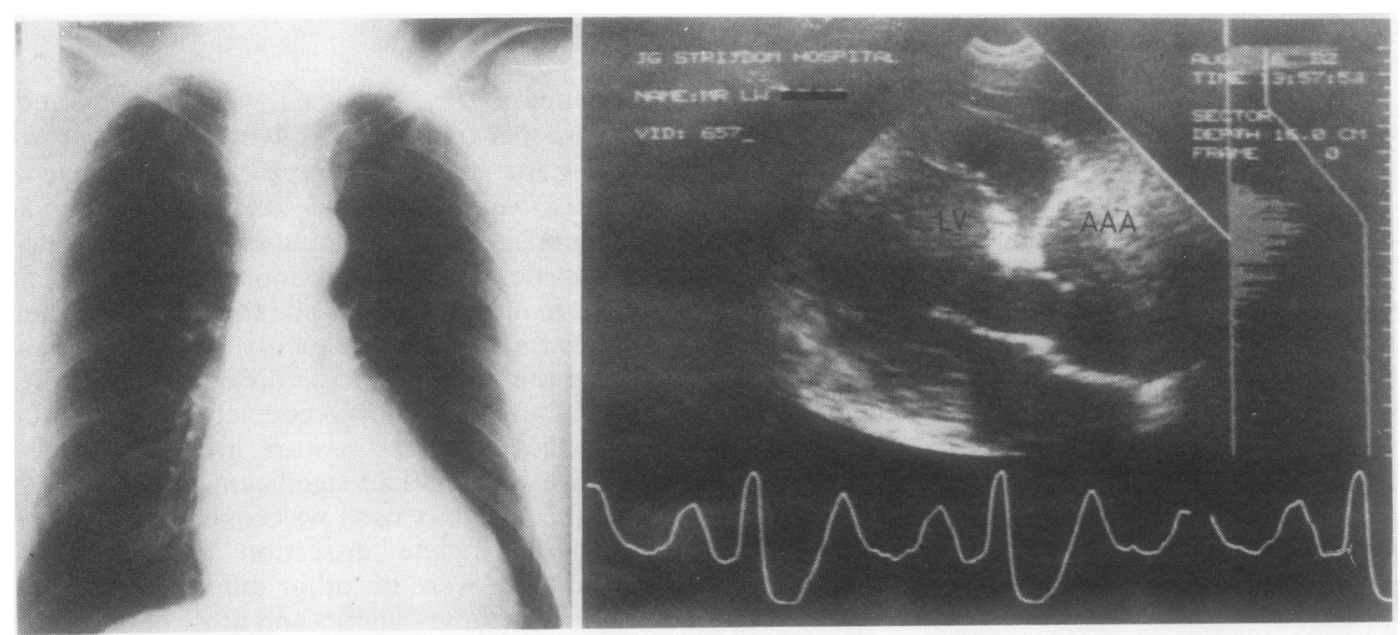

Diagnosis of ascending aortic aneurysm (AAA) by two dimensional echocardiography. The chest radiograph (left) was within normal limits. The echocardiogram (right) shows a large ascending aortic aneurysm, $6 \mathrm{~cm}$ in diameter. $L V$-left ventricle. 
sutures. Eighteen, nine, and four patients respectively received the Hall-Kaster, Björk-Shiley, and St Jude Medical (SJM) prosthesis.

The choice of technique used for repair of the aneurysm was influenced by the anatomical characteristics of the lesion. Fifteen patients received a composite graft (group 1), while in seven the aortic valve and ascending aorta were replaced with separate prostheses (group 2). In the remaining nine patients (group 3), after aortic valve replacement, the aneurysm was repaired by excision of the excessive, abnormal aortic wall segment, followed by direct closure.

In the cases where aneurysmal dilatation extended to the aortic sinuses a composite graft technique (as described by Bentall and de Bono ${ }^{10}$ ) was preferred. When the Hall-Kaster and SJM prostheses were used and where a composite graft was not commercially available it was constructed during the operation. The valve cuff was sewn to a woven Dacron tubular graft of appropriate size (30 or $35 \mathrm{~mm}$ ) with a continuous $3 / 0$ Tycron suture. The prosthetic sewing ring was then sutured to the aortic annulus with the same interrupted suture technique. The coronary ostia, surrounded by a small cuff of the native aortic wall (often not detached), were implanted into the Dacron tube with continuous $5 / 0$ prolene sutures.

In seven patients with a non-dilated aortic root the aortic valve was replaced first. The ascending aorta was then replaced with a woven Dacron conduit, in a supracoronary position by a "bucket handle" technique." In some of these cases the posterior segment of the proximal anastomosis was constructed first with the graft inverted and tucked into the left ventricle through the aortic annulus. The graft was then everted out of the ventricle and the aortic valve prosthesis sutured to the annulus in the usual way. Finally, the anterior half of the proximal anastomosis was completed. With this technique a more accurate and therefore haemostatic suture line was constructed. The risk of haemorrhage from the inaccessible posterior aspect of the anastomosis is minimised. In all cases the distal anastomosis was constructed with a double everting continuous suture of $4 / 0$ prolene, buttressed with a strip of Teflon felt. In no case was the Dacron conduit preclotted. In a few cases the aneurysm wall was closed over the conduit after resection of excess tissue.

In nine patients dilatation of the ascending aorta was asymmetrical-that is, it did not affect the whole circumference. In these cases the thinner anterior and right wall was resected to reduce the aortic diameter ("tailoring"). It was then closed directly, longitudinally, with double continuous $4 / 0$ prolene suture, buttressed with strips of Teflon felt.

With these techniques the mean duration of cardiopulmonary bypass was 98 (SD 26) minutes and the aorta was cross clamped for $68(20)$ minutes. In one patient circulatory arrest at $22^{\circ} \mathrm{C}$ was used for 29 minutes.

All patients were followed up in our outpatients department. The survivors of group 3 were recently restudied; chest radiography, echocardiography, and computed tomography were performed to diagnose recurrence of the aneurysm. The remaining patients were examined clinically during routine outpatient visits. The follow up data were retrieved from the respective records. Statistical analysis was performed by the $\chi^{2}$ method with the use of $2 \times 2$ contingency tables.

\section{Results}

Six patients died early, giving an operative mortality of $19.4 \%$ (table 1). Of these, two died on the operating table. Both had acute dissections and suffered cardiac arrest before or during anaesthesia induction and could not be weaned from cardiopulmonary bypass. Three of the other four patients, who died soon after operation, also had emergency operations for acute dissection. In one of these patients the dissection extended to the iliac arteries, while another dissection had ruptured into the pericardial cavity. All died with renal failure among other things. Hence the operative mortality for emergency operations for acute dissection was $55.6 \%(5 / 9)$. The last of the four died of respiratory insufficiency. He presented with moderate left ventricular failure and was operated on electively for a saccular aneurysm and free aortic regurgitation. Thus the mortality rate for patients who had elective surgery was $4.5 \%$ $(p<0 \cdot 01)$. In none of these cases was death directly related to technical complications during surgery. There was no significant difference in the mortality rates for the three types of repair (table 2).

Despite the fact that preclotting of conduits was not routinely used in this series, appreciable haemorrhage occurred in only four patients $(12.9 \%)$. Three survived without further complica-

Table 2 Operative mortality related to the type of repair (no significant differences between groups)

\begin{tabular}{lll}
\hline $\begin{array}{l}\text { Type of } \\
\text { repair* }\end{array}$ & $\begin{array}{l}\text { No of } \\
\text { patients }\end{array}$ & $\begin{array}{l}\text { No (\%) } \\
\text { of deaths }\end{array}$ \\
\hline 1 & 15 & $3(20 \cdot 0)$ \\
2 & 7 & $2(28 \cdot 6)$ \\
3 & 9 & $1(11 \cdot 1)$ \\
Total & & $6(19 \cdot 4)$ \\
\hline
\end{tabular}

*See footnote to table 1 . 
tions, but one died in the intensive care unit from renal failure that preceded surgery (see above). There were no important neurological complications resulting from surgery.

Only one patient has died at a late stage. He had "tailoring" of the aneurysm and the postoperative course was uncomplicated. The time and cause of his death are unknown. Two patients were lost to follow up and the remaining 22 patients were available for clinical assessment after a mean follow up period of 2.5 (range 1-4) years. All but three are in class I according to the New York Heart Association criteria. One patient, who was not anticoagulated, had had a major embolic episode, with a minimal residual neurological deficit. All patients had radiographs taken recently and there was evidence of recurrence of the aneurysm in only one patient. In this patient, who is symptom free, there was considerable widening of the mediastinum. Computed tomography showed a recurrent aneurysm of the ascending aorta measuring $6 \mathrm{~cm}$ in diameter at its widest. The patient had had a "tailoring" procedure (group 3) performed three years previously for a moderate sized aneurysm, probably due to Marfan's syndrome. No electrocardiographic evidence of ischaemia was found in patients who had composite grafts and coronary artery reimplantation (group 1). There are no cases of perivalvular leaks or infection.

\section{Discussion}

The natural history of acute ascending aortic dissection associated with aortic valve regurgitation is dismal. More than $65 \%$ of patients die in the first 24 hours and only $8 \%$ survive longer than one week. ${ }^{12}$ On the other hand, non-operative hypotensive medical treatment of this disorder has an early mortality of $67 \%$ and progression of the disease occurs in $25-35 \%$ of survivors. ${ }^{1314}$ For this reason most surgical units consider dissecting aneurysms of the ascending aorta with regurgitation as a surgical emergency.4 $5^{13} 15^{-17}$ Any delay in intervention results in an increase in the mortality and morbidity rates, especially in cases with established or impending rupture and in those with coronary disease or occlusion of a major arterial branch. ${ }^{5}$ In these cases preoperative angiography is not essential and echocardiography may be sufficient to confirm the diagnosis of dissection. ${ }^{18}$ Hypotensive treatment becomes only a temporary measure while preparations are made for surgery. ${ }^{513} 19$

The need for aortic valve replacement in cases of acute dissection with regurgitation is controversial. In most cases valve dysfunction is due to loss of commissural support. Hence many favour resuspension of the aortic leaflets. ${ }^{4-61720-22}$ There are, how- ever, several reports of late failure and subsequent valve replacement. ${ }^{523}$ We routinely replace the valve where there is more than moderate regurgitation.

Non-dissecting aneurysmal dilatation of the ascending aorta may affect the aortic sinuses and annulus (annuloaortic ectasia) ${ }^{24}$ Consequently, it is believed that if recurrence of the aneurysm ${ }^{25-27}$ is to be avoided the entire ascending aorta should be replaced down to the annulus. ${ }^{102829}$ This requires reimplantation of the coronary arteries, which may create additional complications, such as stenosis of the orifice and the formation of pseudoaneurysms. ${ }^{27}{ }^{30}$ Although we have not encountered any instances of recurrence of the aneurysm in patients who had separate aortic valve replacement and supracoronary implantation of tubular grafts, we now prefer a composite graft for total replacement of the valve and supraannular ascending aorta to forestall this theoretical complication. This composite graft technique might appear to be more complicated, but the complexity is more apparent than real..$^{23} 3031$ In our series similar aortic cross clamp times were recorded with the two techniques. Appreciable haemorrhage occurred in four patients and these were anastomotic bleeds. This confirmed our earlier findings ${ }^{32}$ and consequently we prefer not to use preclotted grafts when using low porosity woven Dacron.

The nine patients who had "tailoring" of the aorta were operated on earlier in the series. This simple procedure, which aims at reducing the diameter of the aorta and therefore the wall tension (Laplace's law), conflicts somewhat with the principle of composite replacement to minimise the risk of recurrence. But the diffuse characteristics of the disease also make tubular replacement of a segment of the ascending aorta an "incomplete" operation..$^{33}$ To the best of our knowledge this technique has not been previously described. We have not yet observed any cases of progressive enlargement of the "tailored" ascending aorta (and some patients operated on before the period of this study have now been followed up for up to six years). Recently, however, in one patient who had appreciable enlargement of the superior mediastinum computed tomography confirmed a recurrent aneurysm of the ascending aorta. None of the remaining patients with "tailor- 0 ing" of the ascending aorta who have been studied $\overparen{D}$ subsequently has any signs of recurrence of the? aneurysm. At this stage the significance of this case is not clear, particularly since this complication has been reported with all other types of $\stackrel{\odot}{\overparen{P}}$ repair. ${ }^{25273034-36}$ We believe, however, that in $\stackrel{\unrhd}{2}$ appropriate anatomical circumstances a simpler technique may lead to better results. At present we 
confine "tailoring" to patients with aortic valve disease and a localised right lateral dilatation of the ascending aorta.

Simultaneous ascending aortic aneurysm repair and aortic valve replacement can be accomplished with an acceptable mortality rate and relatively little morbidity. The overall mortality rate of $19.4 \%$, including that for acute dissection, compares favourably with the rates of most other series, ${ }^{4} 141724$ given the added risk of aortic valve replacement. Nevertheless, mortality for acute dissection (55.6\%) was high, presumably as a result of the high incidence of coronary disease and renal failure, where medical treatment rarely leads to a survival. The mortality rate after elective ascending aortic aneurysm repair and aortic valve replacement was only $4.5 \%$. The most important predictor of surgical mortality is the preoperative state of the patient, with age, preoperative angina, congestive heart failure, and acute dissection as the main risk factors. ${ }^{23}$ None of the three techniques appeared to be superior to the others. Any benefit of one over the other might, however, have been masked by the anatomical features that dictated which procedure was used. We will continue to tailor the procedure to the anatomical features of the case to avoid the theoretical possibility of a recurrence of the aneurysm.

We wish to thank Mrs M Krengel for the preparation of the manuscript.

\section{References}

' Shaw RS. Acute dissecting aortic aneurysm. Treatment by fenestration of the internal wall of the aneurysm. $N$ Engl J Med 1955;253:331-3.

${ }^{2}$ Wheat MW. Treatment of dissecting aneurysms of the thoracic aorta without surgery. $J$ Thorac Cardiovasc Surg 1965;50:364-73.

${ }^{3}$ Wheat MW jun, Harris PD, Malm JR, Kaiser G, Bowman FO jun, Palmer RF. Acute dissecting aneurysms of the aorta. Treatment and results in 64 patients. $J$ Thorac Cardiovasc Surg 1969;58:344-51.

${ }^{4}$ Miller DC, Stinson EB, Oyer PE, et al. Concomitant resection of ascending aortic aneurysm and replacement of the aortic valve: operative and long term results with "conventional" techniques in ninety patients.J Thorac Cardiovasc Surg 1980;79:388-401.

${ }^{5}$ Kidd JN, Reul G, Cooley D, et al. Surgical treatment of aneurysms of the ascending aorta. Circulation 1976;54, suppl 3:118-22.

- Cachera JP, Vouhé PR, Loisane D, et al. Surgical management of acute dissections involving the ascending aorta. J Thorac Cardiovasc Surg 1981;82:576-84.

${ }^{7}$ McFarland J, Wirleson JT, Dinsmore RE, et al. The medical treatment of dissecting aortic aneurysms. $N$ Engl J Med 1972;286:115-9.

${ }^{*}$ Lindsay J jun, Hurst JW. Drug therapy of dissecting aortic aneurysms. Some reservations. Circulation 1968;37:216-9.
9 Anagnostopoulos CE, Prabhakar MJS, Kittle DF. Aortic dissections and dissecting aneurysms. Am J Cardiol 1972;30:263-73.

${ }^{10}$ Bentall $\mathrm{H}$, de Bono A. A technique for complete replacement of the ascending aorta. Thorax 1968;3:338-9.

"Groves LK, Effler DB, Hawk WA, Gulati K. Aortic insufficiency secondary to aneurysmal changes in the ascending aorta: surgical management. J Thorac Cardiovasc Surg 1964;48:362-79.

${ }^{12}$ Shennan T. Dissecting aneurysms London: HMSO, 1934. (Medical Research Council Special Report Series No 193.)

${ }^{13}$ Wheat MW jun. Treatment of dissecting aneurysms of the aorta. Current status. Prog Cardiovasc Dis 1973;16:87-101.

${ }^{14}$ Daily PO, Trueblood HW, Stinson EB, Wverflein RD, Shumway NE. Management of acute aortic dissections. Ann Thorac Surg 1970;10:237-47.

is Applebaum A, Karp RV, Kirklin JW. Ascending vs descending aortic dissections. Ann Surg 1976; 183: 286-300.

${ }^{16}$ Dallen JE, Alpert JS, Cohn LH, Black H, Collins JJ. Dissection of thoracic aorta. Medical or surgical therapy? Am J Cardiol 1974;34:803-8.

17 Seybold-Epting W, Meyer J, Hallman GL, Cooley DA. Surgical treatment of acute dissecting aneurysms of the ascending aorta. J Thorac Cardiovasc Surg (Torino) 1977;18:43-8.

${ }^{18}$ DeMaria AN, Bommer W, Neumann A, Weinert L, Bogren H, Mason DT. Identification and localization of aneurysms of the ascending aorta by cross-sectional echocardiography. Circulation 1979;59:755-61.

19 Parker FB jun, Neville JF jun, Hanson EL, Mohiuddin S, Webb WR. Management of acute aortic dissection. Ann Thorac Surg 1975;19:436-42.

${ }^{20}$ Najafi H, Dye WS, Javid H, Hunter JA, Goldin MD, Julian OC. Acute aortic regurgitation secondary to aortic dissection. Surgical management without valve replacement. Ann Thorac Surg 1972;14:474-82.

${ }^{21}$ Pate JW, Richardson RL, Eastridge CE. Acute aortic dissections. Ann Surg 1976;42:395-404.

${ }^{22}$ Koster JK jun, Cohn LH, Mee RBB, Collins JJ jun. Late results of operation for acute aortic dissection producing aortic insufficiency. Ann Thorac Surg 1978; 26:461-7.

${ }^{23}$ De Bakey M, McCollum CH, Crawford ES, et al. Dissection and dissecting aneurysms of the aorta. Twenty year follow up of 527 patients treated surgically. Surgery 1982;92:1118-34.

${ }^{24}$ Ellis PR, Cooley DA, De Bakey ME. Clinical considerations and surgical treatment of annulo-aortic ectasia. $J$ Thorac Cardiovasc Surg 1961;42:363-70.

${ }^{25}$ Symbas PN. Discussion of Wheat MW jun, Bornchow IB, Ramsey HW. Surgical treatment of aneurysms of the aortic root. Ann Thorac Surg 1971;12:593-607.

${ }^{26}$ Inberg MV, Haria T, Laaksonen $\mathrm{V}$, Möttönen $M$, Wegelius U, Vänttinen E. Surgical treatment of aneurysms of the ascending aorta with special reference to cystic medial necrosis of the aorta. Scand $J$ Thorac Cardiovasc Surg 1977;11:25-31.

${ }^{27}$ McCready R, Pluth JR. Surgical treatment of ascending aortic aneurysms associated with aortic valve insufficiency. Ann Thorac Surg 1979;28:307-16.

${ }^{28}$ Inberg MV, Vänttinen E, Arola M, Wegelius U. Total replacement of the ascending aorta and aortic valve 
with implantation of the coronary ostia in Marfan's syndrome. A preliminary report of four cases. Scand J Thorac Cardiovasc Surg 1978;12:15-22.

${ }^{29}$ Kouchoukos NT. Progress in treatment of ascending aortic aneurysms due to dissection, arteriosclerosis, or cystic medial necrosis. World J Surg 1980;4:527-34.

${ }^{30}$ Mayer JE jun, Lindsay WG, Wang Y, Jorgensen CR, Nicoloff DM. Composite replacement of the aortic valve and ascending aorta. J Thorac Cardiovasc Surg 1978;76:816-23.

${ }^{31}$ Inberg MV, Vänttinen E, Laaksonen V, Rantakokko V. Annulo-aortic ectasia involving the aortic arch. Scand J Thorac Cardiovasc Surg 1982;16:119-23.

\section{Notice}

\section{Dr HM (Bill) Foreman Memorial Fund}

The trustees of the Dr HM (Bill) Foreman Memorial Fund invite applications for grants relating to studies on respiratory disease. Limited funds are available for registered medical practitioners to assist in travelling to countries other than their own to study respiratory disease, and also for the support of clinical research abroad. Intending applicants should write for further details to $\mathrm{Dr} \mathrm{BH}$ Davies, Sully Hospital, Sully, South Glamorgan.
${ }^{32}$ Antunes MJ, Colsen PR, Kinsley RH. Hypothermia and circulatory arrest for surgical resection of aortic arch aneurysms. J Thorac Cardiovasc Surg 1983;86:57681.

${ }^{33}$ Bahnson HT. In Discussion of McCready and Pluth. ${ }^{27}$

${ }^{34}$ Crosby IK, Ashcraft WC, Reed WA. Surgery of proximal aorta in Marfan's syndrome.J Thorac Cardiovasc Surg 1973;66:75-81.

${ }^{35}$ Helseth HK, Haglin JJ, Stenlund RK, et al. Ascending aortic aneurysms with associated aortic regurgitation. Ann Thorac Surg 1973;16:368-74.

${ }^{36}$ Liddicoat JE, Bikassy SM, Rubio PA, et al. Ascending aortic aneurysms: review of 100 consecutive cases. Circulation 1975;51, suppl 1:202-9. 